\title{
Von Hippel-Lindau gene expression in human endometrium during menstrual cycle
}

\author{
YAN-YAN LU, WEI-JIE ZHU and BAO-GUO XIE \\ Department of Developmental and Regenerative Biology, College of Life Science and \\ Technology, Jinan University, Guangzhou, Guangdong 510632, P.R. China
}

Received July 31, 2013; Accepted February 7, 2014

DOI: $10.3892 / \mathrm{mmr} .2014 .1962$

\begin{abstract}
The von Hippel-Lindau (VHL) gene is a tumor suppressor gene, which is widely expressed in the kidney, lung, breast, eye, ovary and cervix. Mutations of the VHL gene are able to induce VHL disease and tumorigenesis. However, it has yet to be evaluated whether the VHL gene is expressed in the human endometrium. The objective of the present study was to investigate whether the VHL gene is expressed in the human endometrium and to identify changes in expression levels during the menstrual cycle. A total of 35 human endometrial tissue samples in the proliferative $(n=17)$ and secretory phase $(n=18)$ were subjected to the present study. VHL gene expression levels were assessed using Western blot analysis and reverse transcription polymerase chain reaction (RT-PCR). It was observed that the expression of VHL mRNA in the human endometrium decreased from the proliferative to secretory phase $(\mathrm{P}<0.05)$. Levels of VHL protein in the proliferative phase were higher than those in the secretory phase $(\mathrm{P}<0.05)$. In conclusion, the present study revealed that the VHL gene is expressed in the normal human endometrium, and its expression levels change during the different periods of the menstrual cycle.
\end{abstract}

\section{Introduction}

The human endometrium consists of complex tissue composed of various cell components, and changes during the proliferative and secretory phase of the menstrual cycle (1). It is capable of blastocyst implantation, immunological tolerance, regulation of trophoblast invasion and infectious agent control (2). A number of factors participate in the remodeling of the endometrium, including steroid hormone, cytokines, tumor suppressor gene and growth factors.

Correspondence to: Professor Wei-Jie Zhu, Department of Developmental and Regenerative Biology, College of Life Science and Technology, Jinan University, 601 Hao Huangpu Da Dao Xi, Guangzhou, Guangdong 510632, P.R. China

E-mail: tzhuwj@jnu.edu.cn

Key words: von Hippel-Lindau, endometrium, menstrual cycle
The von Hippel-Lindau (VHL) gene was isolated by positional cloning and identified as a tumor suppressor gene in 1993 (3). The VHL gene, which is a classical tumor suppressor gene and regulates a number of target genes involved in mRNA stabilisation through the selective degradation of RNA bound proteins, including the endothelial growth factor, vascular endothelial growth factor, transforming growth factor $\alpha$ and carbonic anhydrase 9 (4). It is widely expressed in a variety of tissues, demonstrating that the expression of the VHL gene transcript is not restricted to organs affected by the VHL disease (5). Mutations of the VHL gene were associated with carcinogenesis in various organs, including the kidney, lung, breast, eye, ovary and cervix (6). Additionally, a deficiency or inactivation of the VHL gene is able to cause ovarian tumors and uterine cervix carcinoma $(7,8)$. The VHL protein (pVHL), the expression product of the VHL gene, has been ascribed several distinct biochemical activities and involvement in the regulation of the cell cycle (9). The pVHL is a multifunctional protein, which is associated with the inhibition of angiogenesis, cell cycle arrest, fibronectin matrix assembly, activation of p53 and proteolysis (10). However, it has yet to be elucidated whether the VHL gene is expressed in the human endometrium during the menstrual cycle.

The aim of the present study was to investigate whether the VHL gene is expressed in the human endometrium, and to assess its expression levels in the human endometrium during the different phases of the menstrual cycle.

\section{Materials and methods}

Tissue samples. Samples of human normal endometrial tissue were obtained by hysterectomy from patients with benign diseases. A total of 35 fresh tissue samples consisting of proliferative $(n=17)$ and secretory endometrium $(n=18)$ were immediately frozen in liquid nitrogen and subsequently stored at $-80^{\circ} \mathrm{C}$ until further processing for reverse transcription polymerase chain reaction (RT-PCR) and Western blot analysis. The exclusion criterion of patients was treatment with exogenous hormones within six months prior to surgery. All patients signed informed consent letters, and the protocol for the present study was approved by the Local Ethics Committee (Guangzhou, China). Patients with normal endometrial tissue were subjected to surgery for benign reasons not associated with endometrial dysfunction, and their age was 
$43 \pm 2.5$ years (mean \pm standard deviation; range, $30-48$ years). The menstrual day of the patients was correlated with the histologic stage of the endometrium according to the criteria established by Noyes et al (11).

$R N A$ isolation and RT-PCR. Total mRNA was extracted from 35 fresh human endometrial tissue samples in the proliferative phase $(n=17)$ and secretory phase $(n=18)$ using a commercial kit (Omega Bio-Tek, Norcross, GA, USA) according to the manufacturer's instructions. Concentration and purity of the mRNA were assessed using electrophoresis on a $1.0 \%$ agarose gel with an OD260/280 absorption ratio $>1.8$. Aliquots of mRNA $(20 \mu \mathrm{g})$ from each sample were reverse transcribed using Oligo (dT) 18 primer and moloney murine leukemia virus reverse transcriptase (M-MLV RT) (Promega Corp., Madison, WI, USA). The housekeeping gene glyceraldehyde 3-phosphate dehydrogenase (GAPDH) was used as an internal control to normalize the results in terms of variations in the amount of input RNA and efficiency of reverse transcription. The primers used were: GAPDH, forward: 5'-CTGGCGCTGAGTACGTCG-3' and reverse: 5'-TTGACAAAGTGGTCGTTGA-3' (657 bp), and VHL gene, forward: 5'-GTCGAAGAGTACCGCCCTGAAG-3' and reverse: 5'-GTGTCCCTGCATCTCTGAAGAG-3' (300 bp). PCR amplification was performed under the following conditions: Initial denaturation at $94^{\circ} \mathrm{C}$ for $2 \mathrm{~min}$, followed by 32 cycles of denaturation at $94^{\circ} \mathrm{C}$ for $30 \mathrm{sec}$, annealing at $59.5^{\circ} \mathrm{C}$ for $30 \mathrm{sec}\left(60^{\circ} \mathrm{C}\right.$ for GAPDH), extension at $72^{\circ} \mathrm{C}$ for $1 \mathrm{~min}$ and a final extension at $72^{\circ} \mathrm{C}$ for $7 \mathrm{~min}$. The PCR products were verified by electrophoresis on a $1.5 \%$ agarose gel and densitometric analysis was performed using the Bio-Rad Gel Doc 2000 Imaging System (Bio-Rad, Hercules, CA, USA). Densitometrical values were used to calculate the ratios between target and GAPDH bands.

Western blot analysis. Western blot analysis was performed with the same endometrial tissue samples as those used for PCR. The fresh endometrium was homogenized and lysed on ice using cell lysis buffer and protease inhibitor cocktail. Following centrifugation at $12,800 \mathrm{xg}$ for $5 \mathrm{~min}$ at $4^{\circ} \mathrm{C}$, protein concentrations were assessed using the Bicinchoninic Acid Protein Assay kit (Pierce Biotechnology, Inc., Rockford, IL, USA). Total protein was denatured in Laemmli buffer, fractionated using a $10 \%$ one-dimensional SDS-PAGE and transferred onto a nitrocellulose membrane (Amersham Biosciences, Piscataway, NJ, USA). The gels were blocked for $2 \mathrm{~h}$ in TBST solution ( $20 \mathrm{mmol} / \mathrm{l} \mathrm{Tris}(\mathrm{pH} 7.6), 137 \mathrm{mmol} / \mathrm{l}$ sodium chloride, $0.1 \%$ Tween 20 ) containing $10 \%$ non-fat dry milk and incubated with antibodies against human VHL (1:1000; Cell Signaling Technology, Inc., Danvers, MA, USA) overnight at $4^{\circ} \mathrm{C}$ and against $\beta$-actin (1:3,000; Santa Cruz Biotechnology, Inc., Santa Cruz, CA, USA) for $1 \mathrm{~h}$ at room temperature with agitating. The gels were then washed three times for 10 min each in TBST followed by incubation for $1 \mathrm{~h}$ at room temperature with anti-rabbit immunoglobulin G (IgG; 1:1,000; Boster Biological Engineering Co., Ltd., Wuhan, China) and anti-mouse IgG horseradish peroxidase-linked species-specific antibodies (1:500; Boster Biological Engineering Co., Ltd.). The bound antibodies were detected with the enhanced chemiluminescence system BeyoECL Plus (Beyotime, Shanghai, China).

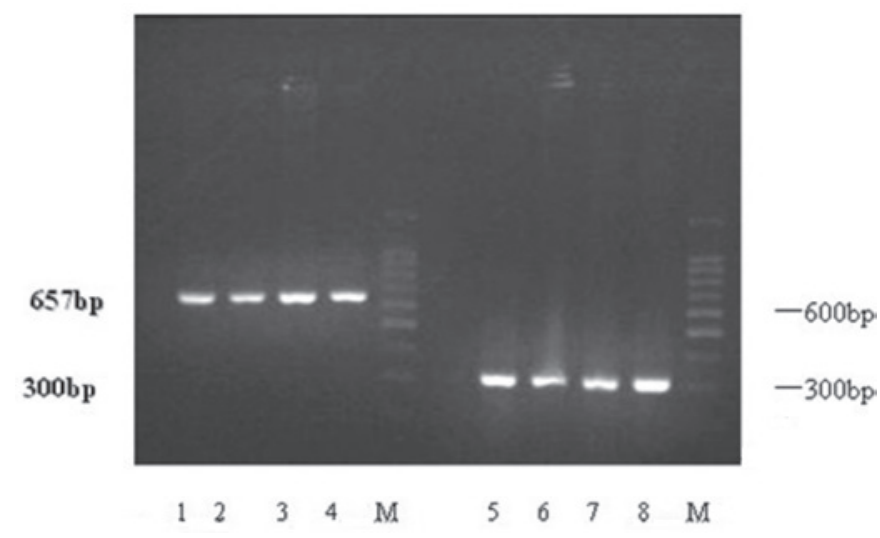

Figure 1. Electrophoresis of amplified PCR products. RT-PCR analysis of GAPDH and VHL mRNA levels in human endometrium. GAPDH mRNA (lanes 1-4) and VHL mRNA (lanes 5-8) expressed in human endometrium samples. The VHL mRNA expression in proliferative endometria (lanes 5, 6 and 7) and secretory endometrium (lane 8 ). $\mathrm{M}$, marker.

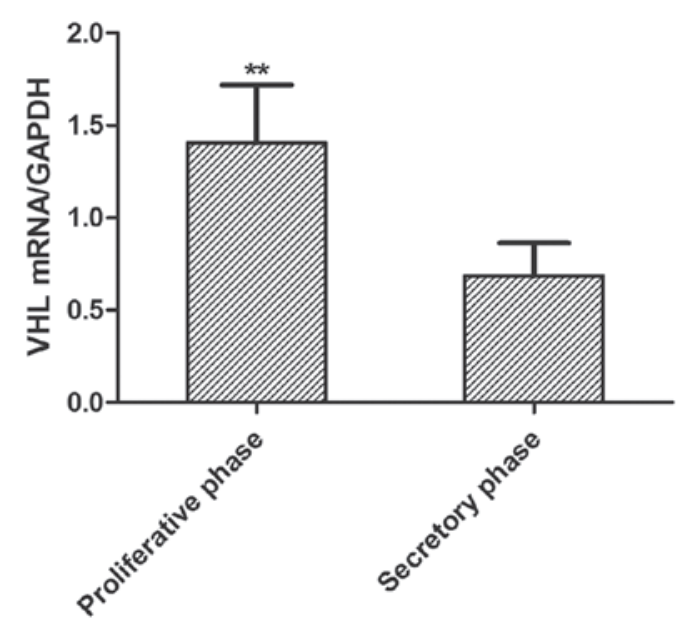

Figure 2. VHL mRNA levels in proliferative and secretory endometria were assessed using RT-PCR. The GAPDH gene was used as an internal control for RT-PCR. The expression of VHL mRNA in the proliferative phase was higher than that in the secretory phase $\left({ }^{* *} \mathrm{P}<0.01\right)$.

Band intensities were quantified by scanning densitometry using the Bio-Rad Quantity One software (Bio-Rad, Hercules, CA, USA).

Statistical analysis. Statistical analysis was performed using SPSS 17.0 (SPSS, Inc., Chicago, IL, USA). Values were presented as the mean \pm standard deviation, and the one-way analysis of variance test (ANOVA) was used. Differences were considered as statistically significant for $\mathrm{P}<0.05$.

\section{Results}

RT-PCR analysis. Expression of VHL mRNA in the human endometrium was analyzed by RT-PCR. A total of 35 fresh endometrial samples were analysed in regard to GAPDH mRNA expression, and when they were positive, they were considered for further assessment of VHL mRNA expression levels (Fig. 1). VHL mRNA expression levels are shown in Fig. 2. The expression of VHL mRNA in the 
A

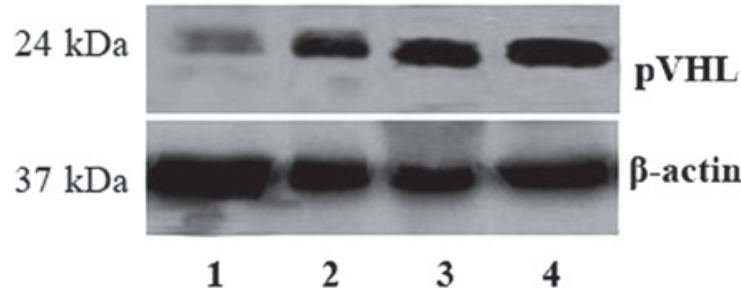

B

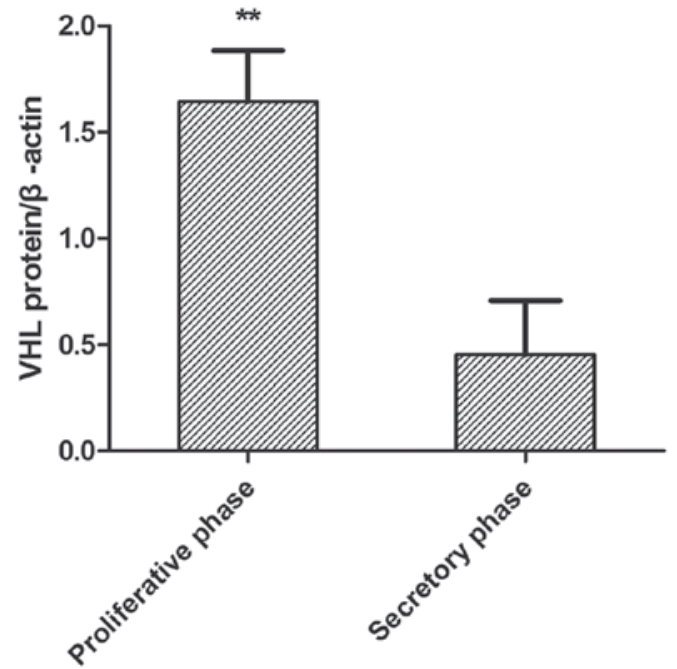

Figure 3. Endometrial samples were subjected to western blot analysis for detection of pVHL and $\beta$-actin. (A) pVHL and $\beta$-actin were detected in the first and the second band, respectively. The intensity of pVHL is shown in the proliferative phase (lanes 3 and 4) and the secretory phase (lanes 1 and 2). (B) pVHL expression levels were elevated in the endometria during the proliferative phase compared with the secretory phase. There was a statistically significant difference between proliferative phase and secretory phase $\left({ }^{* *} \mathrm{P}<0.01\right)$.

proliferative phase was higher than that in the secretory phase $(1.26 \pm 0.46$ versus $0.69 \pm 0.28)(\mathrm{P}<0.05)$. A decrease in the expression of VHL mRNA in the endometrium was observed from the proliferative to the secretory phase of the menstrual cycle.

Western blot analysis. pVHL levels in the fresh endometrial tissue were assessed by western blot analysis and normalized to $\beta$-actin, and a single band with a molecular mass of $24 \mathrm{kDa}$ was observed in all the samples (Fig. 3A). The quantified results are shown in Fig. 3B. pVHL expression levels were significantly increased in the proliferative phase compared with the secretory phase $(1.83 \pm 0.67$ versus $0.43 \pm 0.37)(\mathrm{P}<0.05)$.

\section{Discussion}

The VHL gene is ubiquitously expressed in a variety of organs, with particularly high levels of expression in the urogenital system, brain, spinal cord, sensory ganglia, eyes and bronchial epithelium (12). Its deactivation in patients is able to induce the development of VHL disease, central nervous system haemangioblastoma, renal carcinoma and cysts. pVHL is a multifunctional protein, which is essential for endothelial extracellular matrix deposition and inhibits cell motility (13). pVHL is also able to induce cell differentiation and growth arrest through integration of cell-cell and cell-extracellular matrix signaling (14).

The endometrium undergoes changes in the cyclic blood vessels during the menstrual cycle, influenced by steroid hormones and other angiogenesis genes. A previous study confirmed that the expression levels of the VHL gene in human placental villous tissue were associated with the vascular endothelial growth factor (VEGF), and that it was a positive regulator of VEGF production (15). However, the expression of the VHL gene has yet to be assessed in the human endometrium during the menstrual cycle. Angiogenesis is regulated by a number of cytokines, including VEGF, transforming growth factor and tumor necrosis factor. VEGF is a key mediator of angiogenesis in physiological and pathological conditions, and also regulates endometrial vascular development (16). In addition, VEGF expression at the transcriptional level is able to promote endometrial angiogenesis during the menstrual cycle. The VHL gene regulates VEGF expression at both the transcriptional and post-transcriptional levels, and its inactivation in target cells leads to loss of VEGF suppression (17). The present study has demonstrated that VHL gene expression levels in the endometrium in the proliferative phase are higher than those in the secretory phase $(\mathrm{P}<0.05)$. This result suggests that the VHL gene inhibits the expression of VEGF in the endometrium during the proliferative phase to prevent an excess of vascular proliferation.

The hypoxia inducible factor-1 (HIF1) has a crucial role in the cell responses to the availablity of oxygen and vasculogenesis through the transcriptional activation of specific genes. Expression of HIF1- $\alpha$ protein in the human endometrial glandular epithelium may be responsible for the upregulation of VEGF (18). In addition, HIF1- $\alpha$ protein was increasingly expressed from the proliferative to the secretory phase in the human endometrium (19). pVHL is regarded as a key factor for the oxygen-dependent proteolysis of $\alpha$-subunits of HIF1- $\alpha$, and in pVHL-defective cells, HIF1- $\alpha$ subunits were not downregulated. Therefore, the HIF1- $\alpha$ subunit was identified and targeted for rapid proteasome-dependent degradation by the VHL E3 ubiquitin ligase complex at normal oxygen concentrations (20). Additionally, hypoxic cells were able to regulate VHL gene expression levels through HIF1- $\alpha$ (21). Thus, the deficiency and inactivation of the VHL gene is able to promote cellular HIF1- $\alpha$ expression. In the present study, the expression of VHL mRNA and protein in the endometrium were decreased from the proliferative to the secretory phase. This result indicates that the VHL gene may prevent excessive growth of blood vessels in the endometrium during the proliferative phase.

The pVHL as a tumor suppressor protein regulates extracellular fibronectin matrix assembly and cell cycle. Fibronectin is a regulator of various cell activities including the promotion of cell migration, spreading, and extracellular matrix assembly or tissue turnover. Fibronectin has a crucial role in the control of trophoblast invasion, angiogenesis and determination of cell shape, and thus regulates endometrial receptivity and pregnancy (22). In the human endometrium, fibronectin was detected by immunocytochemical localization in the epithelial and stromal cells of the endometrium. Additionally, fibronectin levels decrease in the endometrium from the proliferative to the secretory phase and modulate the progression of endometrium (23). Overexpression of pVHL 
may increase fibronectin expression post-transcriptionally and the secretion of extracullar fibronectin (24). pVHL mutations lead to diseases associated with fibronectin assembly defects, and pVHL-deficient cells fail to assemble the extracellular fibronectin matrix. In the present study, pVHL expressed in the endometrium during the proliferative phase was higher than that in the secretory phase. This result suggested that pVHL may take an active role in the human endometrium during menstrual cycle through the interaction with fibronectin.

In conclusion, to the best of our knowledge, the present study is the first to assess VHL mRNA and protein expression levels in the human endometrium during the menstrual cycle. Expression of VHL mRNA and protein were decreased in the human endometrium from the proliferative to the secretory phase. This result may provide a novel view on the mechanism of endometrial disease. There is a requirement for further elucidation of whether VHL mRNA and protein expression levels may be a target for novel therapies of endometrial diseases.

\section{References}

1. Maas JW, Groothuis PG, Dunselman GA, de Goeij AF, Struyker Boudier HA and Evers JL: Endometrial angiogenesis throughout the human menstrual cycle. Hum Reprod 16: 1557-1561, 2001.

2. Uz YH, Murk W, Yetkin CE, Kayisli UA and Arici A: Expression and role of interleukin-23 in human endometrium throughout the menstrual cycle and early pregnancy. J Reprod Immunol 87: 21-27, 2010.

3. Latif F, Tory K, Gnarra J, Yao M, Duh FM, Orcutt ML, Stackhouse T, Kuzmin I, Modi W and Geil L: Identification of the von Hippel-Lindau disease tumor suppressor gene. Science 260: 1317-1320, 1993.

4. Kamada M, Suzuki K, Kato Y, Okuda H and Shuin T: von Hippel-Lindau protein promotes the assembly of actin and vinculin and inhibits cell motility. Cancer Res 61: 4184-4189, 2001

5. Lonser RR, Glenn GM, Walther M, Chew EY, Libutti SK, Linehan WM and Oldfield EH: von Hippel-Lindau disease. Lancet 361: 2059-2067, 2003

6. Pavlova TV, Kashuba VI, Muravenko OV, Yenamandra SP, Ivanova TA, Zabarovskaia VI, Rakhmanaliev ER, Petrenko LA Pronina IV, Loginov VI, Iurkevich OIu, Kiselev LL, Zelenin AV and Zabarovskiǔ ER: Technology of analysis of epigenetic and structural changes of epithelial tumors genome with NotI-microarrays by the example of human chromosome. Mol Biol (Mosk) 43: 339-347, 2009 (In Russian).

7. Osada R, Horiuchi A, Kikuchi N, Yoshida J, Hayashi A, Ota M, Katsuyama Y, Mellilo G and Konishi I: Expression of hypoxia-inducible factor $1 \alpha$, hypoxia-inducible factor $2 \alpha$, and von Hippel-Lindau protein in epithelial ovarian neoplasms and allelic loss of von Hippel-Lindau gene: nuclear expression of hypoxia-inducible factor $1 \alpha$ is an independent prognostic factor in ovarian carcinoma. Hum Pathol 38: 1310-1320, 2007.

8. Choi CH, Lee KM, Choi JJ, Kim TJ, Kim WY, Lee JW, Lee SJ, Lee JH, Bae DS and Kim BG: Hypermethylation and loss of heterozygosity of tumor suppressor genes on chromosome $3 \mathrm{p}$ in cervical cancer. Cancer Lett 255: 26-33, 2007.
9. Kaelin WG Jr: The von Hippel-Lindau tumor suppressor protein and clear cell renal carcinoma. Clin Cancer Res 13: 680s-684s, 2007.

10. Kamada M, Suzuki K, Kato Y, Okuda H and Shuin T: von Hippel-Lindau protein promotes the assembly of actin and vinculin and inhibits cell motility. Cancer Res 61: 4184-4189, 2001.

11. Noyes RW, Herting A and Rock J: Dating the endometrial biopsy. Am J Obstet Gynecol 122: 262-263,1975.

12. Richards FM, Schofield PN, Fleming S and Maher ER: Expression of the von Hippel-Lindau disease tumour suppressor gene during human embryogenesis. Hum Mol Genet 5: 639-644, 1996.

13. Tang N, Mack F, Haase VH, Simon MC and Johnson RS: pVHL function is essential for endothelial extracellular matrix deposition. Mol Cell Biol 26: 2519-2530, 2006.

14. Xu JY,Zhu WJ, Cao XZ, Li XF and Wu J: Aberrant expression of the von Hippel-Lindau gene in human endometrial hyperplasia and endometrial carcinoma. Int J Gynecol Cancer 21: 430-434, 2011.

15. Rajakumar A, Doty K, Daftary A, Markovic N and Conrad KP: Expression of von Hippel Lindau (pVHL) protein in placentae from normal pregnant women and women with preeclampsia. Placenta 27: 411-421, 2006.

16. Datta K, Mondal S, Sinha S, Li J, Wang E, Knebelmann B, Karumanchi SA and Mukhopadhyay D: Role of elongin-binding domain of von Hippel Lindau gene product on HuR-mediated VPF/VEGF mRNA stability in renal cell carcinoma. Oncogene 24: 7850-7858, 2005.

17. Choueiri TK, Vaziri SA, Jaeger E, Elson P, Wood L, Bhalla IP, Small EJ, Weinberg V, Sein N, Simko J, Golshayan AR, Sercia L, Zhou M, Waldman FM, Rini BI, Bukowski RM and Ganapathi R: von Hippel-Lindau gene status and response to vascular endothelial growth factor targeted therapy for metastatic clear cell renal cell carcinoma. J Urol 180: 860-865, 2008.

18. Nayak NR and Brenner RM: Vascular proliferation and vascular endothelial growth factor expression in the rhesus macaque endometrium. J Clin Endocrinol Metab 87: 1845-1855, 2002.

19. Critchley HO, Osei J, Henderson TA, Boswell L, Sales KJ, Jabbour HN and Hirani N: Hypoxia-inducible factor-1 $\alpha$ expression in human endometrium and its regulation by prostaglandin E-series prostanoid receptor 2 (EP2). Endocrinology 147: 744-753, 2006

20. André $\mathrm{H}$ and Pereira TS: Identification of an alternative mechanism of degradation of the hypoxia-inducible factor- $1 \alpha$. J Biol Chem 283: 29375-29384, 2008.

21. Genbacev O, Krtolica A, Kaelin W and Fisher SJ: Human cytotrophoblast expression of the von Hippel-Lindau protein is downregulated during uterine invasion in situ and upregulated by hypoxia in vitro. Dev Biol 233: 526-536, 2001.

22. Kaloglu C and Onarlioglu B: Extracellular matrix remodelling in rat endometrium during early pregnancy: the role of fibronectin and laminin. Tissue Cell 42: 301-306, 2010.

23. Li Z, Kreiner M, van der Walle CF and Mardon HJ: Clustered integrin $\alpha 5 \beta 1$ ligand displays model fibronectin-mediated adhesion of human endometrial stromal cells. Biochem Biophys Res Commun 407: 777-782, 2011.

24. Zhou Q, Pardo A, Königshoff M, Eickelberg O, Budinger GR, Thavarajah K, Gottardi CJ, Jones J, Varga J, Selman M, Sznajder JI, Raj JU and Zhou G: Role of von Hippel-Lindau protein in fibroblast proliferation and fibrosis. FASEB J 25: 3032-3044, 2011. 